\title{
Towards a Geographical Orchestration of Mobile Learning Activities
}

\author{
http://dx.doi.org/10.3991/ijim.v8i2.3627 \\ Nassim DENNOUNI ${ }^{1}$, Yvan PETER ${ }^{1}$, Luigi LANCIERI ${ }^{1}$ and Zohra SLAMA ${ }^{2}$ \\ ${ }^{1}$ Lille1 University, Lille, France \\ 2 Djilali Liabes University, Sidi Bel Abbes, Algeria
}

\begin{abstract}
We are in the transition to a new era where mobility extends to many aspects of our daily lives. Learning, for example, takes place throughout life and anywhere. One may wonder how the traditional orchestration of learning can be applied in a mobile context, for example, to better support students during field trips and museum visits. In this paper, we present a geographic orchestration of resources and activities associated to learning system. The objective is to consider collaboration in mobile learning scenario that depends heavily on the location of learners, their profiles and their activity logs. We also defined a software framework for the design and implementation of pedagogic scenarios of field trip. To validate our approach, we present the implementation of a mobile artifact dedicated to the support of new visitors in exploring the historic monuments of a city.
\end{abstract}

Index Terms-Web technologies, field trip, pervasive environment, mobile learning scenario, Collaborative process integration, geographic orchestration, Emerging technologies.

\section{INTRODUCTION}

Today, mobile computing is already at the heart of many location-based software applications (GPS, RFID ...) that are integrated in specific terminals (Smartphone, tablet PC ...). Tomorrow, ambient computing, via the introduction of these new smart devices will be used in industries that require continuity of mobiles activities such as telemedicine, home automation and serious games. Field trips or visits to museums can improve our education system because they can better direct the learning process by enabling mobile learners to construct their own knowledge by collaborating with others.

In this scalable spatiotemporal context, the orchestration enable to manage real-time learning activities such as reading text, viewing video, testing, feedback, group work, etc. but it generates significant costs of tutoring.

On the other hand, we found that the centralized orchestration is not adapted to the context of a field trip because our learner must remain master of his learning choice and should not be subject to obligatory tutorials actions.

Therefore, our goal is to recommend automatically resources and activities based on learner's geographical context in order to minimize the cost of tutoring instructor (teacher) during the course of the field trip.

In this paper, we present an approach that allows implementing a decentralized orchestration to promote the collaboration of learners in a highly personalized and adaptive open environment. In section 2 of this article, we define our theoretical context, mobile learning and the concept of orchestration. Then we make a state of the art on the organization of field trips. Then, in Section 3, we introduce a design framework for mobile learning scenarios of field trip and a teaching system orchestration of activities and resources centered on the location of learners.

Finally, we describe a software framework for mobile learning scenarios of field trip through the implementation of an application that helps to discover the historical monuments of the city by new visitors.

\section{Theoretical CONTEXT And StATE of THE ART}

\section{A. Mobile Learning}

Mobile learning has become a very popular topic of research because there are many areas of research that address the topic from different points of view. Y. Laouris defines mobile learning as a function which depends on several parameters such as time, space, the learning environment, content, technology, learner profile and the method used [15].

A.Derycke considers mobile learning as a e-Learning version that is suitable for learners mobile in the aim to deliver distance learning in other media as computer workstations. Thus, thanks to the many applications developed, the student can continue his training where it is with a mobile device (Smartphone, IPod, IPad, games console) [6].

According to M. Sharples, mobile learning can be defined as the process (at both personal and public) to arrive at knowledge through exploration and linking of different contexts involving other people and interactive technologies [21].

M. Laroussi think that mobile learning is only part of a whole which consists of learning tools, infrastructure support, contexts and people are distributed in time and space. It allows learning in context, but also through contexts [16].

In our opinion, the definition of mobile learning is always about to change because it must adapt each time to new physical, technological and educational contexts that are closely related to various fields of application.

\section{B. The orchestration in the context of field trips}

The scenario of field trips can be divided into three distinct phases: 1) The preparation phase which allows for planning the site visit, 2) the movement itself as a second phase, and finally 3 ) the finalization phase that integrate monitoring activities such as visit reports, presentations, 
tests and / or feedbacks. The first phase is dominated by the work of the teacher, while the other phase rely much more heavily on the activities of learners. The location of the visit can take place only outside the classroom, while the phases of preparation and finalization can occur inside or outside the classroom [8].

Goodyear et Yang define teaching screenwriting as a reflection on the tasks to be done by learners and human and material resources that can help them succeed in such tasks. According to them, learners transfer the responsibility for learning to the teacher or content creator [10]. In the case of field trips, it is neither reasonable nor possible, because students need to be active and creative in a disciplined manner so that the learning process is effective. The term 'orchestration' refers to the real-time management of educational graphs whose activities lie in different planes (individual, group, class, community ...) and link layers of digital and physical information. While instructional design models are concerned central constraints (who learns what and how), orchestration incorporates constraints less "noble" such as segmentation scheduling, discipline, producing traces for parents, the budget energy of the teacher, the physical organization of the classroom, etc. [7].

Specht and Glahn emphasize that the orchestration also covers personalization and adaptation in a learning environment [9]. In Virtual Learning Environments (VLEs), the orchestration concerns the organization of resources and learning tasks (forums, chat ...) to motivate the learner to use the media associated with a course. As part of a field trip, orchestration not only covers the preparation phase, but also the management of the implementation of learning tasks during the course of the visit and the analysis of the results after the field trip. This analysis helps to rearrange learning activities and examine orchestration strategies of learners in the aim to increase the success rate and reduce the dropout rate during the finalization phase. Figure 1 summarizes the concepts related to the orchestration of learning activities during a field trip.

\section{State of the art on Field trips}

In the "Ambient Wood" application, the context is mainly supported by the use of the GPS system to define the location of learners and provide relevant information and services. This is done for the activities of the exploration phase of the fauna and flora in the forest. PDA learners provided information in response to readings from sensors on humidity and light at a specific location or an indication of the physical presence of a student in a particular location (via GPS). This application integrates the notion of context management based on the geographical location but does not allow learners to interact with each other to build new knowledge through the exchange of comments or resources [20].

Chen, Kao et al. [2] [3] study the birds and butterflies using mobile devices. During the field trip, students will take pictures and try to compare them with those already stored in the database accessible via an ad hoc wireless network. This type of application focuses on outdoor activities but gives little interest to the enrichment of the learning scenario of the visit and evaluation activities to be performed by the learner and the analysis of feedback during the finalization phase.

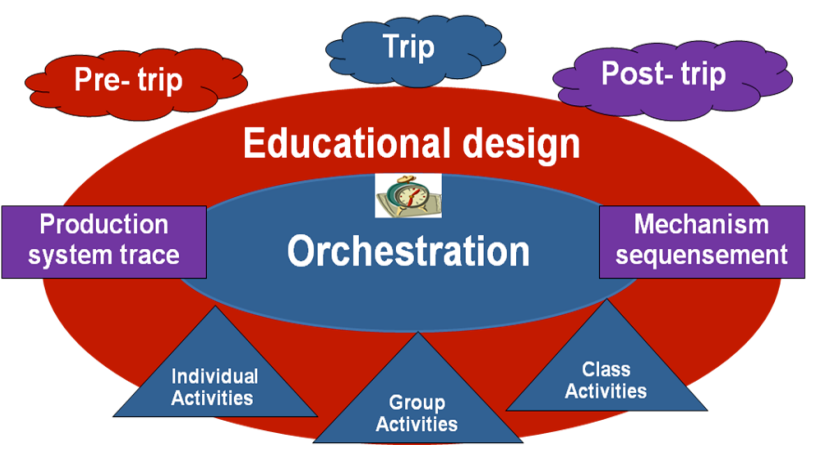

Figure 1. The main elements of orchestration of field trip.

The ENLACE project [22] focuses on enriching the mobile activities with learning resources because it allows a seamless integration of learning objects in the system. However, the architecture adopted for this project does not support real-time changes associated with different suggestions by learners.

In the RAFT project [14], a system was developed to support the creation of mobile applications that facilitate data collection during the field visit and the integration of support for collaborative monitoring activities after the field trip. This project can be considered as a new paradigm of learning, because it supports constructivist learning process in real-world contexts. One of its main objectives is to generate metadata for each new context of the visit. However, the difficulty lies in the combination of activities during the visit and activities to do in class.

In the MoULe project, sensitivity to context supports the location of learners who have a Smartphone with GPS. The system will automatically connect all learners' activities performed during their learning to specific locations within an area of interest. In this way, the system can find the current geographical position of learners and can acknowledge cultural sites in the aim to associate a set of predefined questions on these sites [1]. This project does not provide the opportunity for students to enrich their scenarios by proposing new evaluation activities and new resources for the system operates based on a predetermined scenario during the planning phase of the visit.

LEMONADE ("Learning Environment for Mobile Network-Able Devices") [9] is an environment that allows flexible creation of mobile learning scenarios. It offers flexibility to provide a generic approach for the description of scenarios associated with the full cycle of field trip. LEMONADE combines the activities on the ground with other classroom learning as brainstorming or discussion group activities. However, this tool fits just in the case of an open learning scenario that can not be planned in detail during the design phase.

Contrary to previous work on platforms such as CSCL (Computer Supported Collaborative Learning) that showed their incapacities to manage the activities of mobile learning, the CSCBL (Computer Supported Collaborative Blended Learning) can be used in field trips because they allow a focus on the use of an LMS collaboration and orchestration by the instructor. This kind of project can coordinate the activities taking place in different places thanks to new mobile technologies but it will meet many difficulties when accompanying groups and assigning contextual activities as well as for individualized learning [18]. 
After this state of the art, we found that applications of field trip are very specific to the context and linked to the objectives chosen by the mobile learning. The experiments presented previously do not include open mobile learning scenarios that support real-time collaboration in a spatio-temporal environment as shown in Table I.

To go further in this field, we propose a flexible solution that will support such collaborative activities.

\section{OUR CONTRIBUTION}

\section{A. Designing a field trip scenario}

The attitude of the mobile learners can not be predicted in detail during the design phase but it can be monitored and adjusted during the course of the field trip. For this we must develop a adaptable scenario, often in use, depending on the changing context and needs of visitors. When planning the field trip, we can imagine scenarios that adapt to the particularity of each learning situation with the possibility to integrate any new variants other than those already listed [19].

For this, we use the concept of point of interest (POI Point Of Interest) in the context of this scenario as a localizable physical location by GPS easily identifiable by the different actors of our device. We also classify POI into three categories: 1) POI of localization which is intended to help users while traveling like restaurants, subway stations... 2) the main POI used in the learning scenario such as historical monuments to visit during the field trip 3) additional POI introduced to complete the scenario predetermined by the instructor such as a historical monument that we visiting at the suggestion by one or more learners. Figure 2 shows the three phases associated to our design model.

Static layer of our scenario contains a set of main activities to do in the pedagogic scenario predetermined by the teacher (or orchestrator) and a number of POI to visit during the displacement of learners. This layer is to maintain the consistency of mobile scenario within a supervised learning mode. The variants layer by profile must be defined to be customized to meet the specific requirements of a particular spatio-temporal context which depends on the learner profile and historic of visit. In a given context, teachers can individualize the path of the mobile learner by eliminating variants that are no longer relevant to learning. The open part of our mobile scenario is executed in unexpected situations that are associated with unforeseen contexts during the design phase such as the addition of new centers of interest (POI) or the enrichment of scenario by new activities. The new variants of our scenario must be clearly identified during the finalization stage to better complement our training system.

These three parts form our mobile learning scenario that contains tasks to be done and the supports to be consulted in the context of field trip. To properly ensure respect for pedagogic objectives of our training system, we will rely on the orchestration for the choice of resources and relevant activities adapted to our open collaborative environment.

\section{B. Software framework of our scenario of field trip}

Field trip requires a collaborative scenario centered learning. This scenario can be based on a learning facilita- tor (instructor) or an expert that may be elected from among the active participants in mobile learning scenario.

The selection of experts is based on the number of comments by POI or the number of resources or activities proposed during the visit. It is a realistic learning situation based on active learning that encourages the learner to construct his own knowledge with the group help to achieve the formal objectives of pedagogic visit. The orchestration performed by the instructor or experts can manage real-time graphs relating to mobile learning activities at the level of the learner and within groups formed during the visit. For this, we propose a life cycle for the development of collaborative mobile applications capable of supporting scenarios of pedagogic visit. Figure 3 shows the four phases used in our approach.

TABLE I.

CHARACTERISTICS OF WORKS AROUND THE FIELD TRIP

\begin{tabular}{|c|c|c|c|c|c|c|c|}
\hline Works & $\begin{array}{c}\text { Ambiant } \\
\text { Wood } \\
\text { Project } \\
\text { [20] } \\
\end{array}$ & $\begin{array}{l}\text { Chen } \\
\text { et.all. } \\
\text { [2] [3] }\end{array}$ & $\begin{array}{c}\text { ENLACE } \\
\text { Project } \\
{[22]}\end{array}$ & $\begin{array}{c}\text { RAFT } \\
\text { Pro- } \\
\text { ject }[14 \\
1\end{array}$ & \begin{tabular}{|c} 
MoULe \\
Project \\
[1]
\end{tabular} & $\begin{array}{l}\text { LEMO- } \\
\text { NADE } \\
\text { [9] }\end{array}$ & $\begin{array}{c}\text { CSCBL } \\
{[18]}\end{array}$ \\
\hline $\begin{array}{l}\text { Support the } \\
\text { spatio-temporal } \\
\text { context }\end{array}$ & Yes & Yes & Yes & Yes & Yes & Yes & Yes \\
\hline $\begin{array}{l}\text { Exchange } \\
\text { comments }\end{array}$ & No & Yes & Yes & Yes & Yes & Yes & Yes \\
\hline $\begin{array}{l}\text { enrichment } \\
\text { scenario }\end{array}$ & No & No & Yes & Yes & No & Yes & Yes \\
\hline $\begin{array}{l}\text { real-time col- } \\
\text { laboration }\end{array}$ & No & No & No & Yes & Yes & Yes & Yes \\
\hline $\begin{array}{l}\text { Integration of } \\
\text { three phases of } \\
\text { field trip }\end{array}$ & No & No & No & No & No & Yes & Yes \\
\hline Using POI & No & No & No & No & Yes & No & No \\
\hline $\begin{array}{l}\text { support open or } \\
\text { unexpected } \\
\text { Context }\end{array}$ & No & No & No & No & No & No & No \\
\hline
\end{tabular}

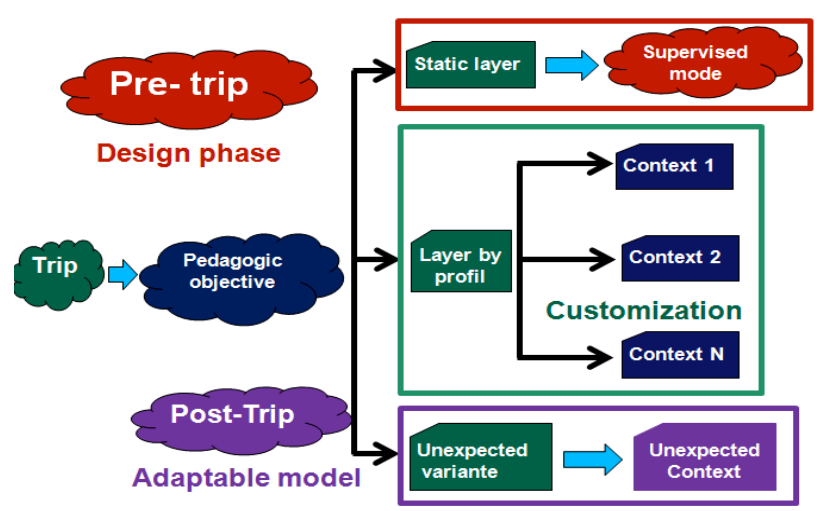

Figure 2. The layers of a fied trip mobile learning scenario.

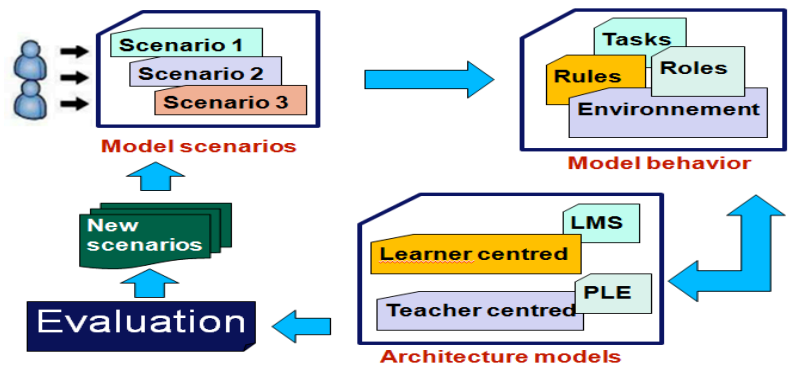

Figure 3. Lifecycle of our mobile collaborative scenario. 


\section{1) Collecting scenarios}

This phase corresponds to the needs analysis. It consists of defining the scenario model as a graphical formalism that describes the roles of actors, artifacts, conditions in which the activities are performed and the relationships between these different elements [5].Our mobile scenario is divided into two parts: a fixed part developed by the instructor during the planning of fief trip and the second part enriched by learners and experts during the visit. In the first part, the instructor introduces significant POI (Main) to visit and see the resources and activities to do in the context of a pre-established supervised Mode scenario. In the second part, students and experts can introduce others POI different from those of the main timeline and join other media and activities. In the first part, the instructor introduces significant POI (Main) to visit and see the resources and activities to do in the context of a preestablished supervised Mode scenario. In the second part, students and experts can introduce other POI different from those of the main timeline and join other media and activities. Mobile users can interact with each other because they can post their comments for each resource or activity of the POI. During finalization phase, a test of knowledge acquired during the field trip is proposed to learners and experts. Finally, analysis of the results of this evaluation will allow us to have a good feedback on our system and identify the level of expertise of learners. The use case diagram of Figure 4 illustrates the role of each user of our system.

\section{2) Development of a behavioral model}

The behavioral model is an overview of the sequence of activities to be supported by the system and their characteristics (roles of actors, context of use, artifacts, etc.)[5]. This model must support spatio-temporal interactions and notifications of contextual events. It must also be sensitive to the context of communication (synchronous or asynchronous messages) and the availability of learning resources.

To ensure the different specificities of our mobile collaborative scenario, we proposed an orchestration system of resources and activity that uses a search algorithm by radius that is described as follows:

\section{Algorithm of geographical Orchestration}

$\underline{\text { Begin }}$

1. Detecting the current position of the learner by GPS

2. Enter $(\mathrm{R})$ the radius Research

3. Determine $(Z)$ the area of interest of the learner.

4. Display POIs belonging to the area $(Z)$

5. For each POI of the area $(\mathbf{Z})$ Do

$$
\text { End Do }
$$

Show all tags related to POI

6. If the learner selects a POI Then

View activities to do by the learner and

resources to consult for this POI

End if

\section{End.}

This algorithm allows to define a pattern of behavior that can be adapted depending on the location of the learner. Moreover, profiles introduced in the database can be used to display the set of POIs that interests the mobile learner. Then, the learner selects manually the POI to visit according to its historical activities during the field trip. Finally, he can view the resources and activities associated with this POI. This information can be entered into the database by the experts, students or even by the instructor.

This database is updated in real time by all actors of our system. Thereby updating the same search with the same input parameters can give different results. However, our model behavior depends heavily on the willingness of learners to participate in the process through the quality of comments posted and groups created by the experts during the field trip.

\section{3) The choice of an architecture model}

The choice of collaborative mobile architecture associed to our behavioral model depends on the nature of the application and the specific needs of learners.

In general, the main learning platforms do not allow to teachers to anchor the activities or resources in the right places for the field trip.

On the other hand, our scenario is characterized by the absence of a global model for conduct learning activities and the freedom left to the learner. Therefore, our architecture model is based on a system that has as input elements: geographic location, learner profile, the history of the visit and the desired search radius.

Other hand, this system outputs the resources and activities associated with the selected POI by the learner as shown in Figure 5.

The choice of one or more POI is made by the learner according to his preferences and his historic during the visit. POI Selected by our learner can be a main point defined by the instructor in the scenario in supervised mode. Additional points added by an expert or another learner can be used in the aim to enrich our scenario. For this, the relevance of recommended activities and resources relative to the formal objectives of the visit are highly dependent of the learner path and his choice of POI. Other hand, the learner has a local view of all POI, resources and activities. It can also work with other students in order to construct their own knowledge, but this demarche can be biased by inappropriate comments.

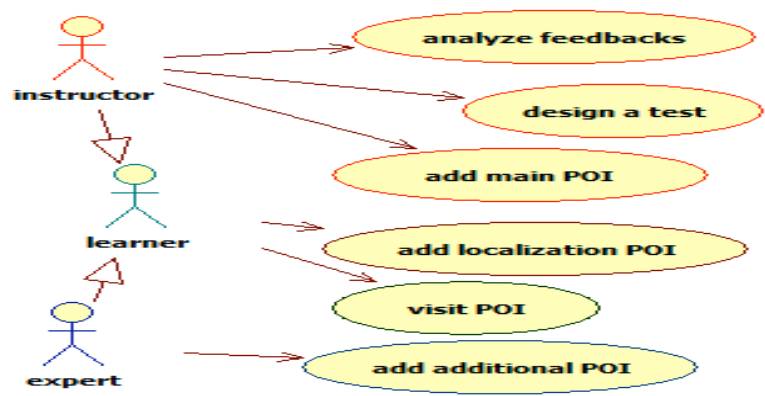

Figure 4. The use case diagram associated at our scenario.

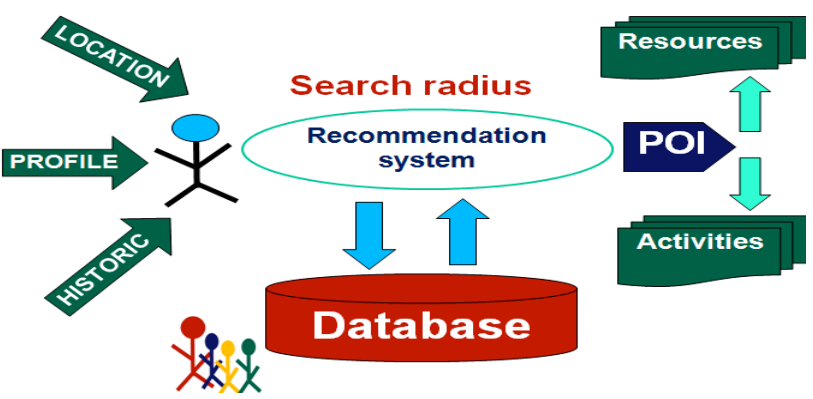

Figure 5. Architecture of our geographical orchestration system. 
For this, the use of collaborative environments as DiGaE (Distributed Gathering Environment) [12] can support the exchange between learners and experts in the finalization phase of the visit.

\section{4) The evaluation of our prototype}

In this phase, we discuss the evaluation of our system based on the research and definition of indicators for the evaluation of our system. These indicators provide a basis for comparison between different learning systems and different configurations of the same system. There are several methods capable of assessing the behavior of collaborative work without worrying that it takes place in a pervasive environment or in a "classic" environment. However, we did not find any method for the specific evaluation of the pervasive aspect in collaboration [11]. Indeed, there are no indicators, no measure or method that should allow us to evaluate our mobile collaborative scenario in all these aspects. To try to remedy this, we calculate a set of measures that reflect the participation of the learner at training and collaboration with the others during the course of our pervasive scenario. These measures are classified into two categories:

1) Global indicators that focus on the evaluation of the contribution of learners or experts in relation to all the resources and activities of the scenario

2) Local indicators that evaluate the individual behavior of the learner.

\section{IMPLÉMENTATION}

To validate our approach for developing field trip applications, we have implemented a project to help visitors of a city to better locate their points of interest (POI) on a Mapping support. This project also aims to provide information about the historical monuments and all places that can act as landmark for the city.

Our work also allows to assist new visitors of a city by providing them learning resources or activities that are associed to points of interest. This ensures a good learning with formal objectives. Our prototype uses mobile technologies found in a smartphone in order to exploit the context of locating a visitor (learner) and profile. to display multimedia tailored to their needs and can help during his visit. Our learners can visit the main POI added by the instructor, he also consults the associated resources and it can make the proposed activities. Our learner can visit the main POIs added by the instructor, he also consults the associated resources and he can make the proposed activities. The learner can become an expert in an area with one or more POI thanks to its potential contribution or its degree of interaction during the course of the visit. Experts can create groups based on their different areas of expertise and can power their workspaces by new resources or activities. The instructor or the orchestrator of our learning can create expert accounts based on the demands of learners.

Figure 6 explains the use cases to add to the diagram shown in Figure 4 to best answer the needs of collaboration between users of our application.

Other hand, users of our application can enrich database with new points of interest through the various updates made from their Smartphone as shown in Figure 7.

For this, they are classified according to different profiles: learner, expert orchestrator visitor... And according

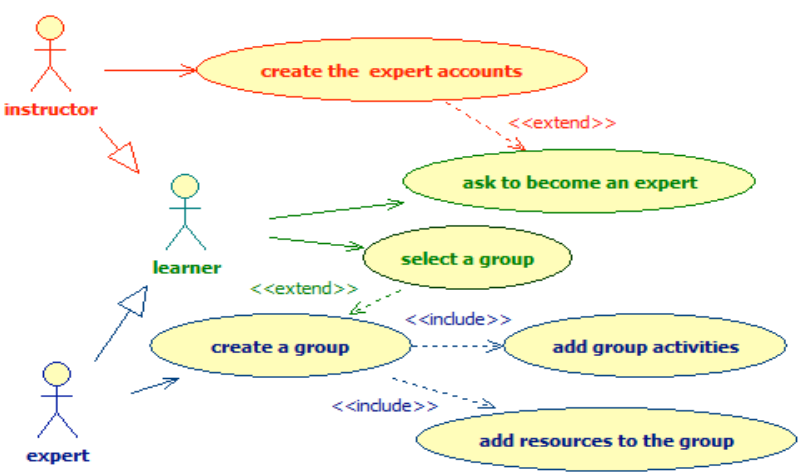

Figure 6. The specific use case in ours application.

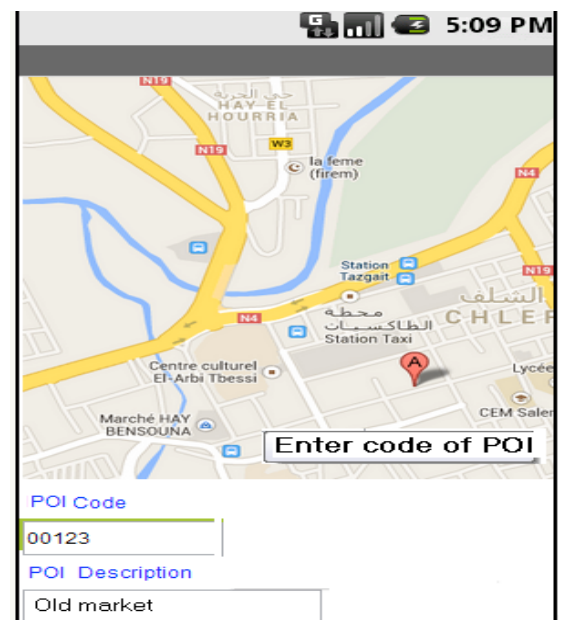

Figure 7. The technical architecture of our application.

to the rights granted by the administrator, they update the server from their mobile devices in order to feed the database with images / videos produced by their Smartphone during the visit as shown in Figure 8:

The architecture of our prototype uses REST Web services based on the HTTP methods (GET, POST, PUT and DELETE) and on the JSON format for the exchange between the server and the Smartphone. With the support of Google Maps, the use of tags is possible to display several information about points of interest (POI) on the smartphone. (See Figure 9)

To evaluate our system, we can calculate, for example, the rates of contributions by role as follows:

$$
\begin{aligned}
& C R L=\sum R L /\left(\sum R L+\sum R O+\sum R E\right) \\
& C R O=\sum R O /\left(\sum R L+\sum R O+\sum R E\right) \\
& C R E=\sum R E /\left(\sum R L+\sum R O+\sum R E\right)
\end{aligned}
$$

CRL: Contribution Rate of Learners.

CRO: Contribution Rate of Orchestrator.

CRE: Contribution Rate of Experts.

RL: Resources added by Learners.

RO: Resources added by the Orchestrator.

RE: Resources added by Experts. 


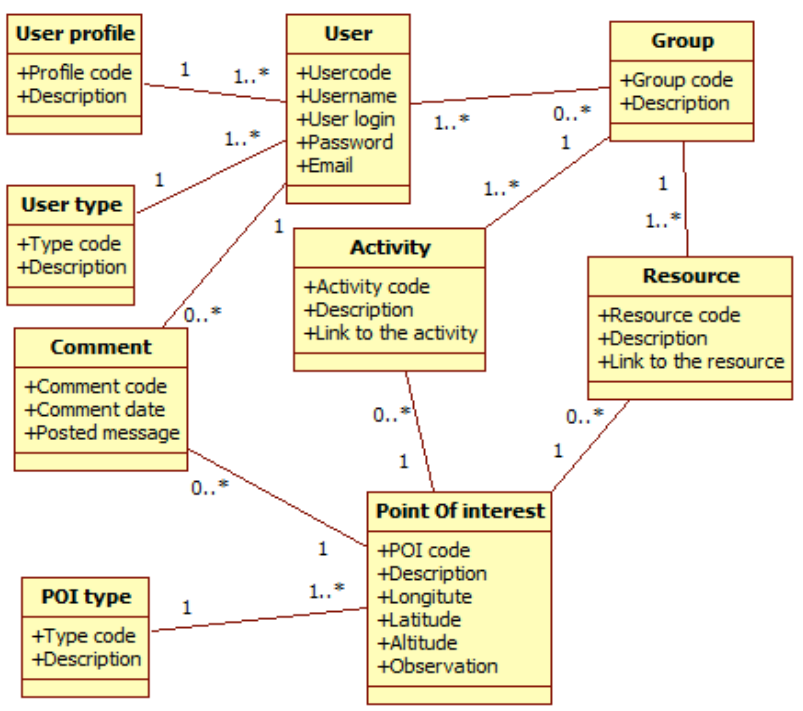

Figure 8. Class diagram associated to ours application.

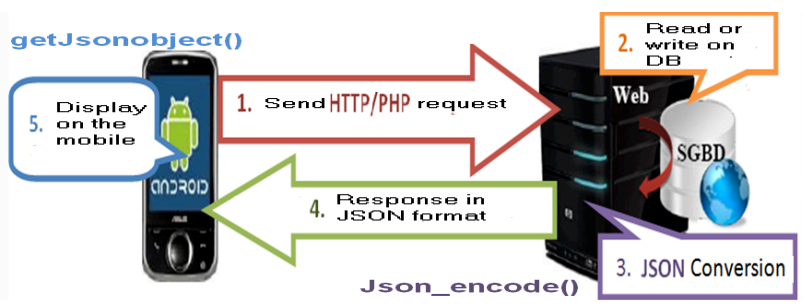

Figure 9. The technical architecture of our application.

These indicators are used to measure and compare the different active participation of different types of actors in our scenario.

Similarly, we can also calculate the contribution rate for Adding POI and for the exchange of different comments.

Most of these parameters that we want to calculate are simple enough to be extracted automatically by the system during our scenario. They allow us to facilitate the visualization of learners' activities in order to deduce new learning profiles. Then it will be possible to see the emergence of new scenarios for electing the experts or for evaluating learners.

\section{CONCLUSION}

Our objective was to define a system that allows an orchestration of mobile learning activities based on the geographical eposition of the learner while respecting the collaborative and open aspect of our mobile scenario.

In this article, we define a conceptual framework for a scenario of field trip and a software framework for the implementation of a development cycle of applications dedicated to mobile learning.

We also presented an implementation of a mobile artifact to validate our approach that is intended for a scenario of field trip.

Other hand, we have designed this artifact in order to implement a mobile learning located in near real time to make contact with a new city. However the limitations of our system may hamper the progress of our learning compared to formal objectives expected of our field trip.
For example, the use of geographic orchestration of resources and activities on the basis of a single location does not take into account the overall vision of pedagogical objectives of our scenario.

The use of ontologies can provide activities and resources based on their relevance with respect to the formal objectives of the mobile scenario [13].

To do this, we believe that the semantic orchestration of mobile learning activities can improve our solution in future work on field trips or visits museums.

\section{ACKNOWLEDGMENT}

This work is partially funded by the FUI Hermès project and Nord-Pas de Calais region

\section{REFERENCES}

[1] M. Arrigo, O. Giuseppe, D. G. Fulantelli, M. Gentile, G. Novara, L. Seta. "A Collaborative MLearning Environment". Paper presented at the 6th Annual International Conference on Mobile Learning, mLearn 2007 pages 13-22., Melbourne Australia, 2007.

[2] Y. S. Chen, T. C. Kao and J. P. Sheu, "A Mobile Learning System for Scaffolding Bird Watching Learning." Journal of Computer Assisted Learning 19(3), 2003, pp. 347-359. http://dx.doi.org/10.1046/j.0266-4909.2003.00036.x

[3] Y. S. Chen, T. C. Kao and J. P. Sheu, "A Mobile ButterflyWatching Learning System for Supporting Independent Learning", In Proceedings of the 2nd IEEE International Workshop on Wireless and Mobile Technologies in Education, JungLi, Taiwan, IEEE Computer Society, 2004

[4] C. Cobos, O. Rodriguez, J. Rivera , J. Betancourt, M. Mendoza ,E. León , E. Herrera-Viedma, "A hybrid system of pedagogical pattern recommendations based on singular value decomposition and variable data attributes" journal of Information Processing and Management,ScienceDirect,2013,pp.607-625

[5] O. Delotte, “ CoCSys : une approche basée sur la construction d'un modèle comportemental pour la conception de systèmes collaboratifs mobiles", thèse de doctorat, Ecole Centrale de Lyon, 2006.

[6] A. Derycke, “ Tutoriel Ubimob 06, Du E-Learning au PervasiveLearning: Concepts, Exemples et Questions de Recherche', 3ème Journées Francophones Mobilité et Ubiquité, Conservatoire National des Arts et Métiers - Paris, 2006

[7] P. Dillenbourg, “Modéliser l'orchestration", Conférence sur Éducation et sciences de l'apprendre Session 4, Ecole Normale Supérieure de Lyon, automne 2012

[8] A. Giemza, L. Bollen, P. Seydel, A. Overhagen, H. Ulrich Hoppe "LEMONADE: A Flexible Authoring Tool for Integrated Mobile Learning Scenarios" The 6th IEEE International Conference on Wireless, Mobile, and Ubiquitous Technologies in Education, IEEE Computer Society, 2010, pp 73-80.

[9] C. Glahn and M. Specht. " Embedding moodle intoubiquitous computing environments". In Publications and Preprints. LMedia, 2010 .

[10] P. Goodyear and D. F. Yang. "Patterns and pattern languages in educational design "In Handbook of Research on Learning Design and Learning Objects: Issues, Applications, and Technologies, volume 2, pages 167-187. IGI Global, 2009.

[11] K.Hamadache, L. Lancieri, “Indicateurs pour l'évaluation du travail collaboratif en environnement Pervasif ", ICT, 2010

[12] S. Kaddouci, Y. Peter, T. Vantroys, P. Laporte, Coupling pedagogical scenarios and location-based services for learning, IEEE Learning Technology Newsletter, October issue, 2010.

[13] S. Kaddouci, Y. Peter, T. Vantroys, Designing learning support for mobile workers, Proceedings 9th IEEE International Conference on Advanced Learning Technologies (ICALT'09).

[14] M. Kravcik, M. Specht, A. Kaibel, L. Terrenghi, "Collecting Data on Field Trips - RAFT Approach" Third IEEE International Conference on Advanced Learning Technologies (ICALT'03), 2003, pp. 478. http://dx.doi.org/10.1109/ICALT.2003.1215201 
[15] Y. Laouris "We Need an Educationally Relevant Definition of Mobile Learning". 4th World conference on mLearning. Cape Town, South Africa; 2005.

[16] M. Laroussi, "Extension d'IMS/LIP pour supporter l'apprentissage pervasif'. INSAT, université de Carthage, Tunis, Tunisie, décembre 2011

[17] N.Manouselis, H.Drachsler, R.Vuorikari, , H.Hummel, ，\& R.Koper, "Recommender systems in technology enhanced learning”. In L. R. F. Ricci \& B.Shapira (Eds.), Recommender systems handbook Berlin: Springer, 2011, pp. 387-415. http://dx.doi.org/10.1007/978-0-387-85820-3_12

[18] M. Pérez-Sanagustın, G. Ramirez-Gonzalez, D. Hernandez-Leo, M. Munoz-Organero, P. Santos, P. Blata and C. Delgado Kloos. "Discovering the campus together: A mobile and computer-based learning experience", Journal of Network and Computer Applications pages 176-188, 2012. http://dx.doi.org/10.1016/j.jnca. 2011.02.011

[19] E. Ouraiba "Scénarisation pédagogique pour des EIAH ouverts Une approche dirigée par les modèles et spécifique au domaine métier", thèse de doctorat, Université du Maine, 2013.

[20] B. Russell \& P. Lonsdale, "Mobile Context Aware Systems: TheIntelligence to Support Tasks and Effectively Utilise Resources ", Mobile Human-Computer Interaction, MobileHCI, 2004, pp. 240-251.
[21] M.Sharples, et al. (2007) 'Mobile Learning: Small devices, Big issues' (in Sharples, M., et al. (eds.) Technology-Enhanced Learning, 2009, Part IV)

[22] M. F. Verdejo, C. Celorrio, E. J. Lorenzo, M. Millan, S. Prades, \& J. Velez, "Constructing Mobile Technology-Enabled Environments for an Integrated Learning Approach", En Innovative Mobile Learning: Techniques and Technologies, IGI Global, 2008, pp. 147-171.

\section{AUTHORS}

N. Dennouni is a $\mathrm{PhD}$ student in computer science and member in the NOCE team of the LIFL laboratory at Lille 1 university (dennouninas@gmail.com)

Y. Peter is an associate professor in computer science and member in the NOCE team of the LIFL laboratory at Lille 1 university. (Yvan.Peter@univ-lille1.fr)

L. Lancieri is a Professor of Computer Sciences and the Head of the NOCE team of the LIFL laboratory at Lille1 university (Luigi.lancieri@univ-lille1.fr)

Z. Slama is an associate professor in computer science and member in the ISIBA team of the EEDIS laboratory at Djilali Liabes university. (z.slama@yahoo.fr)

Submitted 08 March 2014. Published as re-submitted by the authors 05 April 2014. 